\title{
The Porcine Circovirus Type 2 Nonstructural Protein ORF3 Induces Apoptosis in Porcine Peripheral Blood Mononuclear Cells
}

\author{
Wei-Li Lin ${ }^{1}$, Maw-Sheng Chien ${ }^{2}$, Pei-Ching Wu ${ }^{1}$, Chen-Li Lai ${ }^{1}$ and Chienjin Huang ${ }^{*}, 1$ \\ ${ }^{I}$ Graduate Institute of Microbiology and Public Health, College of Veterinary Medicine, National Chung Hsing \\ University, Taichung, Taiwan \\ ${ }^{2}$ Graduate Institute of Veterinary Pathobiology, College of Veterinary Medicine, National Chung Hsing University, \\ Taichung, Taiwan
}

\begin{abstract}
Porcine circovirus type 2 (PCV2) is the primary causative agent of porcine circovirus-associated diseases in pigs. To analyze whether the PCV2 nonstructural protein ORF3 is able to induce apoptosis in nature target cells, transient expression of ORF3 in porcine peripheral blood mononuclear cells (PBMC) was performed, and apoptosis was confirmed by terminal dexoynucleotidyl transferase (TdT)-mediated BrdUTP-nick end labeling (TUNEL) assay. The apoptotic responses induced by the full length or the C-terminal half of ORF3 were significantly higher $(p<0.001)$ than that of cells transfected with the control plasmid. In contrast, the N-terminal half of ORF3 restrictively localized in the cytoplasm and remarkably reduced its ability to induce apoptosis, the apoptotic activity might be correlated with the nuclear localization of ORF3. Furthermore, two clusters of basic residues on the C-terminal half region at the amino acid residues 53-68 and 85-104 could mediate the nuclear localization of fusion protein, confirming their potential role as a nuclear localization signal.
\end{abstract}

Keywords: Apoptosis, Nuclear localization signal, ORF3 protein, Porcine circovirus type 2, Transient expression.

\section{INTRODUCTION}

Porcine circovirus (PCV) is a member of the Circoviridae family, and the virion is icosahedral, nonenveloped and $17 \mathrm{~nm}$ in diameter [1]. PCV type 1 (PCV1) is non-pathogenic in swine and was first described in 1974 as a persistent contaminant of a porcine kidney PK15 cell line $[2,3]$. On the other hand, PCV type 2 (PCV2) is closely associated with a disease syndrome in pigs described as "postweaning multisystemic wasting syndrome" (PMWS) now known as porcine circovirus-associated diseases (PCVAD) [4, 5]. The characteristic symptoms of the syndrome include severe progressive weight loss, dyspnea, tachypnea, anemia, diarrhea, and lymphadenopathy in pigs of 5-15 weeks of age [4, 6, 7]. Lymphoid depletion is the histological hallmark of PMWS and PCV2 infection [8-11]. PMWS is endemic in the majority of the swine-producing countries, causing a severe economic impact on the swine industry worldwide [12].

The genome of PCV2 is a single-stranded circular DNA of about $1.76 \mathrm{~Kb}$, and contains two major open reading frames (ORFs). They are ORF1, the rep gene, which encodes the Rep proteins responsible for virus replication; and ORF2, the cap gene, which encodes the immunogenic capsid (Cap) protein [13-15]. A recent report showed that PCV2 induced apoptosis in the cultured porcine kidney cell (PK-15) via a viral protein encoded by ORF3 in the antisense direction of

*Address correspondence to this author at the Graduate Institute of Microbiology and Public Health, National Chung Hsing University, 250 Kuo Kuang Road, Taichung 40227, Taiwan, Republic of China;

Tel: + 886422853906 ; Fax: + 886422851741 ;

E-mail: cjhuang@dragon.nchu.edu.tw
ORF1 [12]. Further studies demonstrated that ORF3 protein could interact with the porcine homologue of Pirh2, a p53induced ubiquitin-protein E3 ligase, leading to increased p53 levels and apoptosis of the infected cells [16]. Monocyte/macrophage lineage cells are the major target cells for PCV2 infection [17]. The purpose of this study was to prepare a specific immune serum against PCV2 ORF3 for further analyzing the role of ORF3 in inducing apoptosis in porcine peripheral blood mononuclear cells (PBMC).

\section{MATERIAL AND METHODS}

\section{Construction of Recombinant Expression Plasmids by Polymerase Chain Reaction (PCR) Cloning}

PCV2 genomic DNA was extracted with a commercial DNA extraction kit (QIAamp Tissue kit, QIAGEN) from 20 $\mathrm{mg}$ of frozen lymph nodes that was collected from a severe PMWS-affected piglet in a commercial farm in central Taiwan. The PCR primer pairs were designed according to the PCV2 SC strain sequence (GenBank no. AF465211) and used for amplification of the defined coding region of PCV2 ORF3 (Table 1). The PCR reaction was carried out as described previously [18]. The full length of PCV2 ORF3 gene DNA fragment was gel-purified and digested with restriction enzymes $E c o \mathrm{RI} / X h o \mathrm{I}$ followed by cloning into the expression vector pET24a (Novagen) to generate the recombinant plasmid pET24/ORF3. The nucleotide sequences of the ORF3 gene were determined using an automatic DNA sequencer (ABI-377, PE Applied Biosystems). Recombinant plasmids pcDNA/ORF3, pcDNA/ORF3N52, and pcDNA/ORF3N53-104 were used for transient expression of ORF3 and deletion mutants in cells. Those plasmids were constructed by cloning the full length, the $\mathrm{N}$ - or $\mathrm{C}$-terminal half of the coding regions of 
ORF3 into the pcDNA4/HisMax expression vector (Invitrogen). Recombinant plasmids ORF3N53-68/GFP, ORF3N53-85/GFP, and ORF3N85-104/GFP were used to express the defined C-terminal fragments of ORF3 fused to the green fluorescence protein (GFP). Those plasmids were constructed by cloning the DNA fragment encoding the amino acid (aa) residues 53-68, 53-85, and 85-104 of ORF3 into the expression vector pEGFPN3 (BD Biosciences Clontech), respectively. All the recombinant plasmids were sequenced to confirm the accuracy of the open reading frame of ORF3 coding sequences. Recombinant plasmids pcDNA/Cap and pcDNA/RepN314 containing the full length of PCV2 ORF2 (cap) and ORF1 (rep) gene, respectively have been constructed previously $[18,19]$.

\section{Preparation of Specific Mouse Immune Serum Against PCV2 ORF3 Protein}

Recombinant pET24/ORF3 expression plasmid was transformed into $E$. coli BL21 (DE3) competent cells. Expression was induced with $1 \mathrm{mM}$ isopropyl $\beta$-Dthiogalactopyranoside (IPTG), and the protein products were purified and characterized by SDS-polyacrylamide gel electrophoresis (SDS-PAGE) and Western immunoblotting assay, respectively. Expression protein was further purified as described previously [18]. Three $\mathrm{BALB} / \mathrm{c}$ mice were injected three times interperitoneally every two weeks with $0.2 \mathrm{mg}$ of purified ORF3 protein mixed with Freund's adjuvant (Gibco BRL) at ratio 1:1. The animals were bled and sera were harvested at 1 week after the final injection. The specificity of mouse immune serum was determined by indirect immunofluorescence (IFA) with the Porcine Circovirus FA substrate slides (VMRD, USA) according to the manufacturer's manual.

\section{Transfection and Transient Expression}

Peripheral blood was collected into a collection tube with EDTA and peripheral blood mononuclear cells (PBMC) were separated by ficoll-paque (Sigma). The cells were washed twice with phosphate-buffered saline (PBS) and transfected with each purified recombinant pcDNA/ORF3derivative expression plasmid DNA $(1 \mu \mathrm{g})$ using jetPEI ${ }^{\mathrm{TM}}$ (Polyplus-transfection) as specified by the manufacturer. All transfected cells were incubated at $37^{\circ} \mathrm{C}$ for $24 \mathrm{~h}$ or $48 \mathrm{~h}$ followed by indirect immunofluorescence assay and TUNEL assay for detection of apoptosis.

\section{Indirect Immunofluorescence Assay}

Transfected cells were washed three times with PBS followed by fixing with $4 \%$ paraformaldehyde for $10 \mathrm{~min}$. After washing with PBS, the fixed cells were treated with PBS buffer containing $0.25 \%$ Triton X-100 and 5\% dimethyl sulfoxide (DMSO) for $10 \mathrm{~min}$ to increase the permeability of the cellular membrane. After washing with PBS, the cells were treated sequentially with blocking solution, with appropriate dilution of protein specific mouse antiserum, respectively and with $1000 \mathrm{x}$ dilution of Alexa 488conjugated goat anti-mouse IgG (Invitrogen). The cells were visualized with Olympus IX 70 phase-contrast fluorescence microscope.

\section{Terminal Dexoynucleotidyl Transferase (TdT)-Mediated BrdUTP-Nick End Labeling (TUNEL) Assay and Caspase Activity Assay for Apoptosis}

Transfected cells were stained with the APO-BrdU ${ }^{\mathrm{TM}}$ TUNEL Assay Kit (Invitrogen) for detection of apoptosis according to the manufacturer's manual. The cells were visualized with Olympus IX 70 phase-contrast fluorescence microscope. Transfected cells lysates were further analyzed

Table 1. Sequences of Oligonucleotides Used for Cloning the Defined Coding Region

\begin{tabular}{|c|c|c|c|}
\hline $\begin{array}{l}\text { Recombinant } \\
\text { Plasmid }\end{array}$ & $\begin{array}{c}\text { Insert DNA } \\
\text { Encoding } \\
\text { Protein Region }\end{array}$ & PCR primer pair $\left(5^{\prime}-3^{\prime}\right)^{a}$ & $\begin{array}{l}\text { Restriction } \\
\text { Site }\end{array}$ \\
\hline pcDNA/ORF3 & ORF3 aa 1-104 & $\begin{array}{l}\text { ORF3F1: CCGAATTCATGGTAACCATCCCA } \\
\text { ORF3R104: TCCTCGTGTTACTGATGGAGTGT }\end{array}$ & $\begin{array}{c}\text { EcoRI } \\
\text { XhoI }\end{array}$ \\
\hline pcDNA/ORF3N53-104 & ORF3 aa 53-104 & $\begin{array}{l}\text { ORF3F53: CCCGAATTCATGTTTCAAAAGTT } \\
\text { ORF3R104:CCGGATCCAATTTTGCAGGGGAC }\end{array}$ & $\begin{array}{c}\text { EcoRI } \\
X h o \mathrm{I}\end{array}$ \\
\hline $\mathrm{pcDNA} / \mathrm{Cap}$ & Cap aa $1-233$ & $\begin{array}{l}\text { CapF1: CGGGATCCATGACGTATCCAAGGA } \\
\text { CapR233: GTTCTCGAGTTAGGGTTTAAGTGG }\end{array}$ & $\begin{array}{c}\text { Bam HI } \\
\text { XhoI }\end{array}$ \\
\hline pEGFP/ORF3N85-104 & ORF3 aa $85-104$ & $\begin{array}{l}\text { ORF3F85: CCGAATTCATGCACAGCAGTAGA } \\
\text { ORF3R104: TCCTCGTGTTACTGATGGAGTGT }\end{array}$ & $\begin{array}{l}\text { EcoRI } \\
\text { BamHI }\end{array}$ \\
\hline pEGFP/ORF3N53-68 & ORF3 aa $53-68^{b}$ & $\begin{array}{l}\text { ORF3N53:AATTCATGTTTCAAAAGTTCAGCCAGCCCGCGGAAATTTCTGACAAACGTTACG } \\
\text { ORF3R68: }\end{array}$ & $\begin{array}{l}\text { EcoRI } \\
\text { BamHI }\end{array}$ \\
\hline
\end{tabular}

${ }^{a}$ The primer sequences recognized by the specific restriction enzyme are boxed.

${ }^{b}$ The DNA fragment encoding the ORF3 aa 53-68 was generated by denaturing the mixture of ORF3N53 and the antisense ORF3R68 followed by annealing at room temperature. 
with the ApoTarget ${ }^{\mathrm{TM}}$ Caspase Colorimetric Protease Assay Sampler kit (Invitrogen) for determining proteolytic activity of caspases according to the manufacturer's manual. The absorbance was recorded at $405 \mathrm{~nm}$ using a MRX Revelation ELISA reader (Dynex). The statistical significance of differences between transfected porcine PBMC was tested by student's t-test.

\section{Statistical Analysis}

The statistical significance of differences between transfected PBMC was tested by applying student's t-test. Differences were considered significant when $\mathrm{p}<0.05$. Statistical analyses were performed using SigmaPlot ${ }^{\circledR}$ (Systat Software Inc., USA).

\section{RESULTS}

\section{Detection of ORF3 Protein in PCV2-Infected Cells Using Mouse Antiserum Against ORF3}

The mouse antiserum against recombinant ORF3 protein was employed to detect the viral ORF3 in PCV2-infected swine testicle cells (PT-1) fixed on the slide (VMRD) by IFA (Fig. 1). This antiserum stained specifically antigens localized in the nuclei of infected cells, whereas the corresponding preimmune mouse serum did not stain the infected cells.
(A)

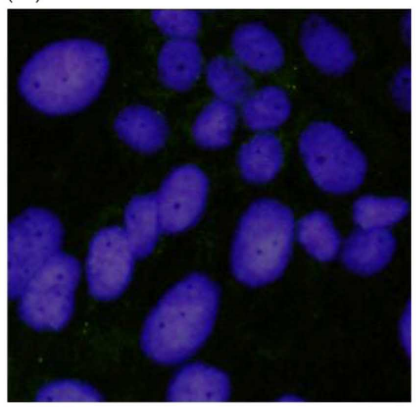

(B)

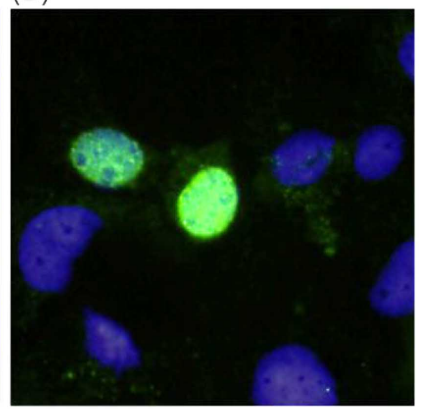

Fig. (1). IFA staining of PCV2-infected cells using the mouse immune serum against expressed ORF3 protein. The PCV2infected cell fixed on the slide (VMRD) was reacted with mouse preimmune serum (A), and mouse anti-ORF3 serum (B), respectively, for detecting the ORF3 protein in infected cells. Magnification 400×.

\section{ORF3 Protein Alone Can Induce Apoptosis in Porcine PBMC}

To analyze whether ORF3 is able to induce apoptosis, transient expression of the full length and the $\mathrm{N}$ - or $\mathrm{C}$ terminal half of ORF3 protein in porcine PBMC was performed. In addition, transient expression of Cap and Rep were also included in parallel for comparison. At 24 or $48 \mathrm{~h}$ post-transfection, the transfected cells were detected by IFA using specific mouse immune serum against each viral protein and apoptosis induced by transient expression of viral protein was confirmed by TUNEL-labeling which detected the DNA breakage. The efficiency of transfection for porcine PBMC was approximately $20 \%$ and $4 \times 10^{2}$ transfected cells expressing specific viral protein were evaluated for apoptosis. About $34.6 \%$ and $42.6 \%$ of the transfected cells expressing ORF3 protein were apoptotic at
24 and $48 \mathrm{~h}$ post-transfection respectively in contrast to an average of $8.4 \%$ in those of cells transfected with control plasmids including $\mathrm{pcDNA} / \mathrm{Rep}, \mathrm{pcDNA} / \mathrm{Cap}$ and pcDNA4/HisMax (Fig. 2). No appreciable levels of TUNELpositive cells were detected in pcDNA/Rep, pcDNA/Cap or pcDNA4/HisMax transfected cells for PBMC. Quantification of TUNEL-positive cells showed that the percentage of apoptotic cells transfected with pcDNA/ORF3 was significantly higher $(p<0.001)$ than that of cells transfected with the control plasmid pcDNA4/HisMax. In addition, the degree of apoptotic response of the N-terminal half of ORF3 protein (ORF3N52) expressing cells were remarkably decreased to the same level as that of pcDNA4/HisMaxtransfected cells. In contrast, the C-terminal half of ORF3 (ORF3N53-104) retained its ability to induce apoptosis similar to the full length of ORF3. Further, caspase activity assays demonstrated significant activation of caspase- $3,-8$, and -9 at $48 \mathrm{~h}$ post-transfection by the full length and the Cterminal half of ORF3 protein (Fig. 3).

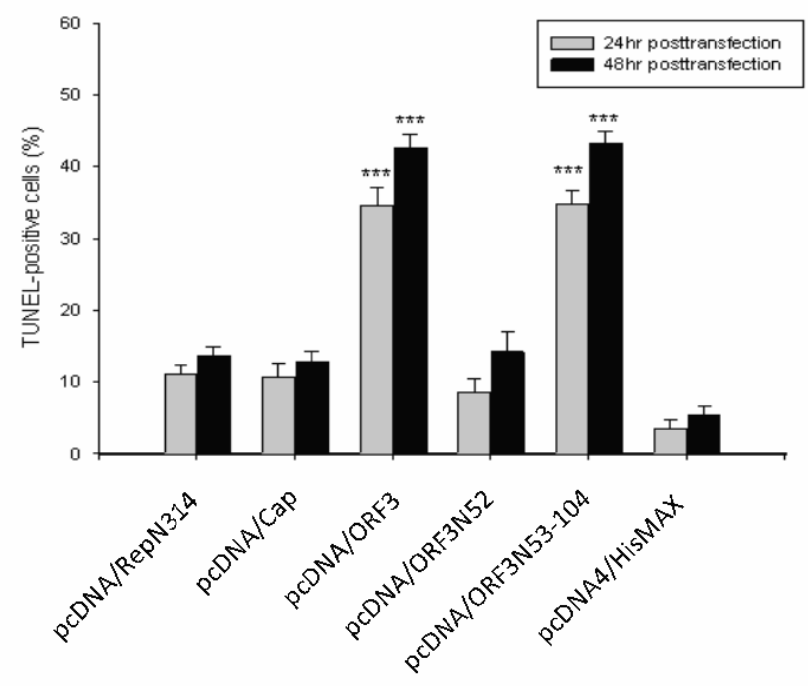

Fig. (2). Histogram of percentage of TUNEL-positive of porcine PBMC transfected cells at $24 \mathrm{~h}$ (gray) and $48 \mathrm{~h}$ (black) posttransfection. ***Significant difference $(p<0.001)$ from pcDNA4/HisMax.

\section{Intracellular Distribution of ORF3 and Deletion Mutants}

To determine the intracellular distribution of ORF3 protein, PK-15 cells were transfected with pcDNA/ORF3, pcDNA/ORF3N52, and pcDNA/ORF3N53-104, respectively; and analyzed by IFA using mouse immune serum against ORF3 at $48 \mathrm{~h}$ post-transfection. The full-length and the Cterminal half of ORF3 were dominantly localized in the nucleus. In contrast, the N-terminal fragment ORF3N52 was detected in the cytoplasm. The results indicate that the Cterminal half of ORF3 contains essential sequences for nuclear localization. Examination of the C-terminal half amino acid sequences revealed two regions, N53-68 $\left.{ }_{53} \mathrm{FQ} \underline{K} F S Q P A E I S D \underline{K R} \underline{R}_{68}\right)$ and N85-104 (85 $\underline{H S S}_{\mathbf{R} Q V T P L}$ SLRSRSSTL ${ }^{-} Q_{104}$ ), containing basic aa residues (which are underlined) with homology to other nuclear localization signals (NLS) [20]. To confirm whether these fragments function as an NLS, the N53-68, N53-85, and N85-104 fragments were fused to the green fluorescent protein (GFP) 
(A)

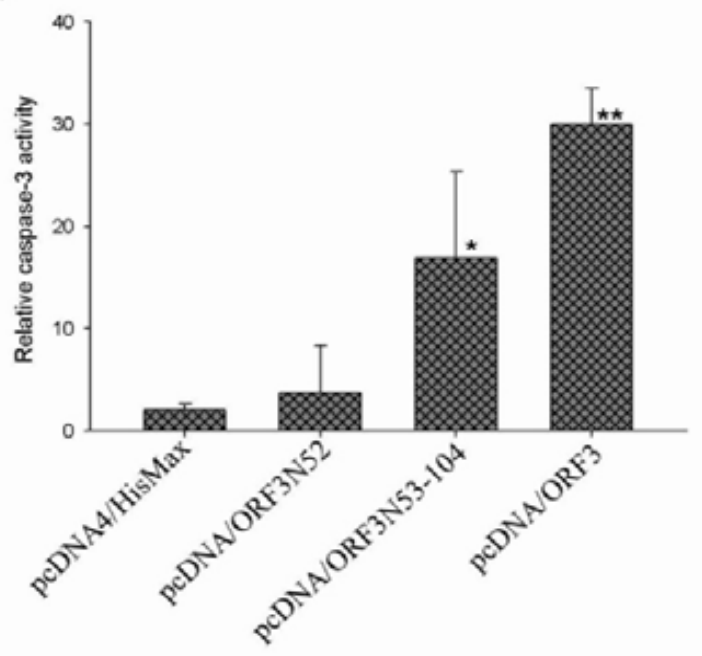

(B)

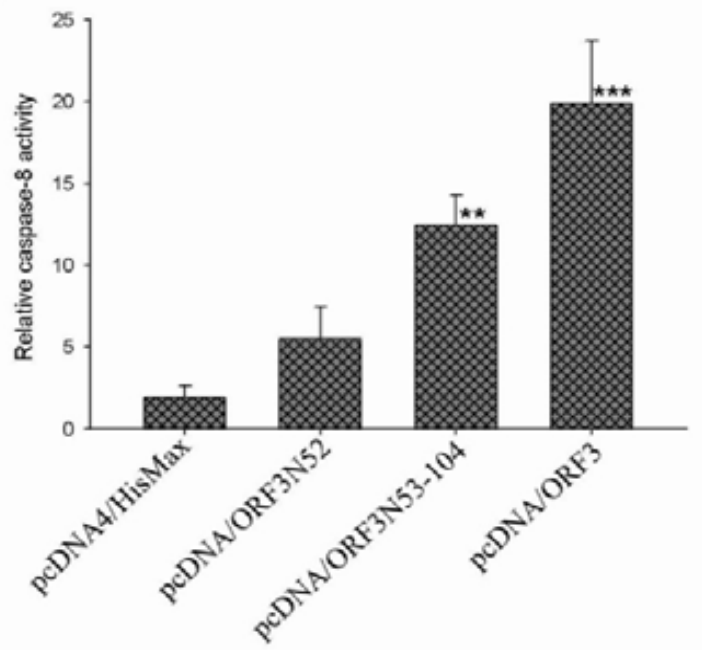

(C)

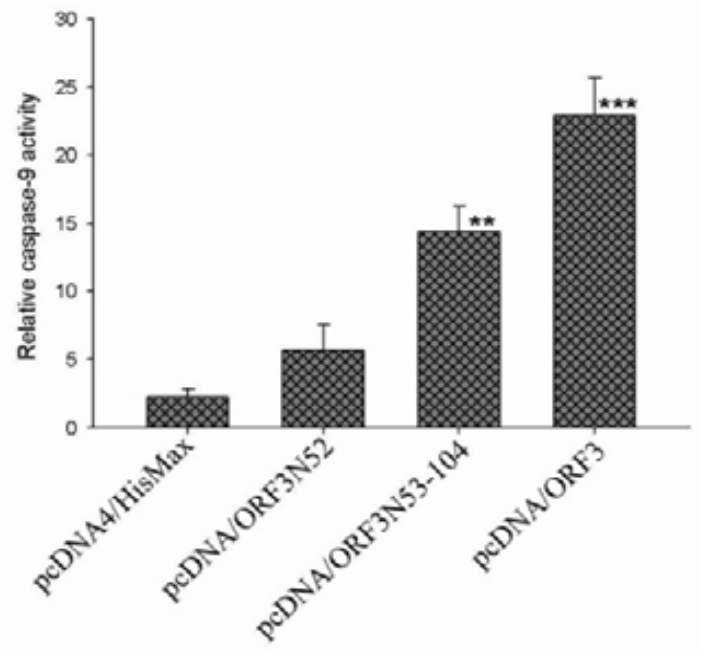

Fig. (3). Analysis of caspase activities of PBMC transfected cells at $48 \mathrm{~h}$ post-tranfection. The bars show the relative caspase-3 (A), -8 (B), -9 (C) activity as the ratio of absorbance at $405 \mathrm{~nm}$ of each plasmid-transfected cells to mock PBMC. *Significant different $(\mathrm{p}<0.05)$ from pcDNA4/HisMax. ${ }^{* *} \mathrm{p}<0.01,{ }^{* * *} \mathrm{p}<0.001$. and their intracellular distribution in PK-15 cells at $48 \mathrm{~h}$ post-transfection was visualized with a fluorescence microscope. GFP was localized predominantly in the cytoplasm, while GFP fusion proteins containing the N5368 , N53-85, or N85-104 region of ORF3 were distributed mostly in the nucleus (Fig. 4).

\section{DISCUSSION}

PCV2 is recognized as the essential infectious agent behind the development of PMWS. The main immunopathological features of PMWS are T- and Blymphocyte depletion in lymphoid tissue and peripheral blood lymphopenia [21, 22]. PCV2 is considered to cause immunosuppression by replicating and inducing apoptosis in lymphocytes [23]. The PCV2 nonstructural protein ORF3 was demonstrated to induce apoptosis in infected PK-15 cells by competing with p53 in binding to Pirh2 and mediating the deregulation of $\mathrm{p} 53$ homeostasis $[12,16]$. However, the effects of ORF3 on the main immunopathological target cells are not clear. In the present study, the PCV2 ORF3 gene was cloned and expressed to generate a specific immune serum for further studying structural and function of ORF3. The mouse immune serum against expressed ORF3 protein could specifically recognize the viral ORF3 protein which was located predominantly in the nucleus of PCV2-infected cells (Fig. 1). The PCV2 ORF3 gene was further cloned to construct the recombinant plasmid pcDNA4/ORF3 for transient expression of ORF3 in PBMC. Transient expression of ORF3 in porcine PBMC at $24 \mathrm{~h}$ post-transfection, more than $34 \%$ of the ORF3expressing cells detected by the mouse immune serum against ORF3 were TUNEL-positive (Fig. 2). In contrast, the Cap- or Rep-expressing cells showed no appreciable levels of TUNEL-positive cells with the control plasmid pcDNA4/HisMax-transfected cells. Since the TUNEL assay should only identify cells in the last phase of apoptosis [24], our results suggest that transient expression of ORF3 alone in vitro can induce apoptosis in PBMC. Further caspase activity analyses also revealed the apoptosis response through activation of initiator caspase- 8 followed by activation of the effector caspase-3 pathway. Japanese encephalitis virus (JEV) infection has also been demonstrated activation of caspase- 8 , and -9 proceeding the FADD-independent and mitochondrion-dependent apoptosis pathway [25]. Activation of caspase-3, -8 , and -9 in the porcine PBMC by the PCV2 ORF3 may facilitate the process of apoptosis eventually leading to immunosuppression of PCV2-infected pigs. Liu et al., (2006) have demonstrated that $\mathrm{BALB} / \mathrm{c}$ mice inoculated with wild-type PCV2 showed the depletion of $\mathrm{CD}^{+}$and $\mathrm{CD} 8^{+} \mathrm{T}$ cells but not in the ORF3-deficient mutant inoculated group [26]. The apoptotic activity of ORF3 may directly contribute to viral pathogenesis. The molecular mechanism of ORF3-induced apoptosis in porcine PBMC merits further investigation.

PCV2 ORF3 is located in the nucleus. The N-terminal half of ORF3 (ORF3N52) was detected in the cytoplasm and could not induce apoptosis in transfected porcine PBMC. In contrast, the C-terminal half of ORF3 (ORF3N53-104) was located in the nucleus and retained its ability to induce apoptosis response. These results suggest that nuclear localization may be required for apoptosis induction and the C-terminal half region of ORF3 contains essential sequences 
Subcellar localization

(A)
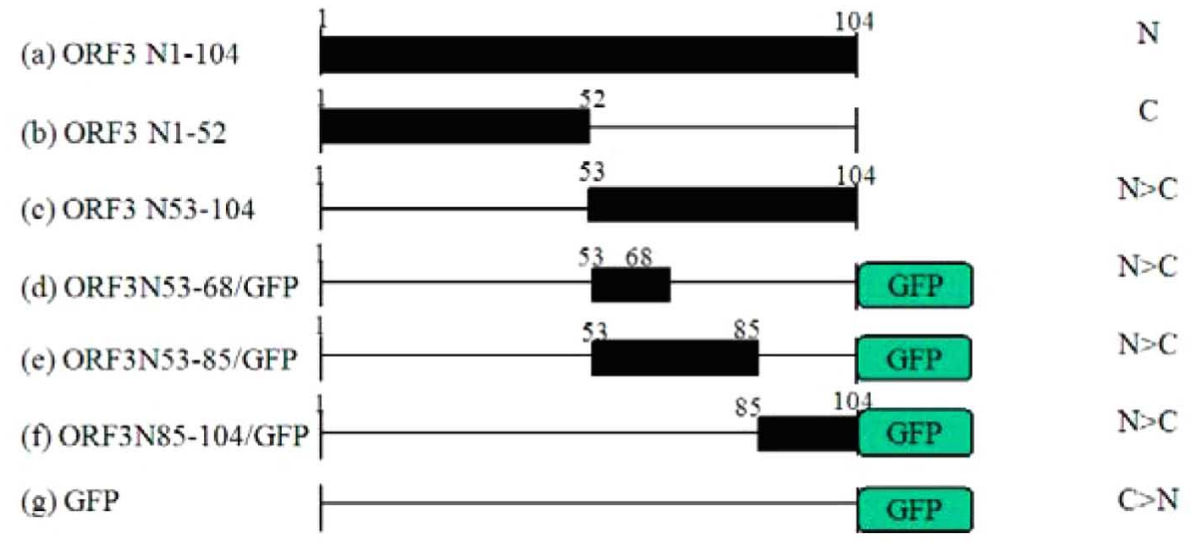

(B)
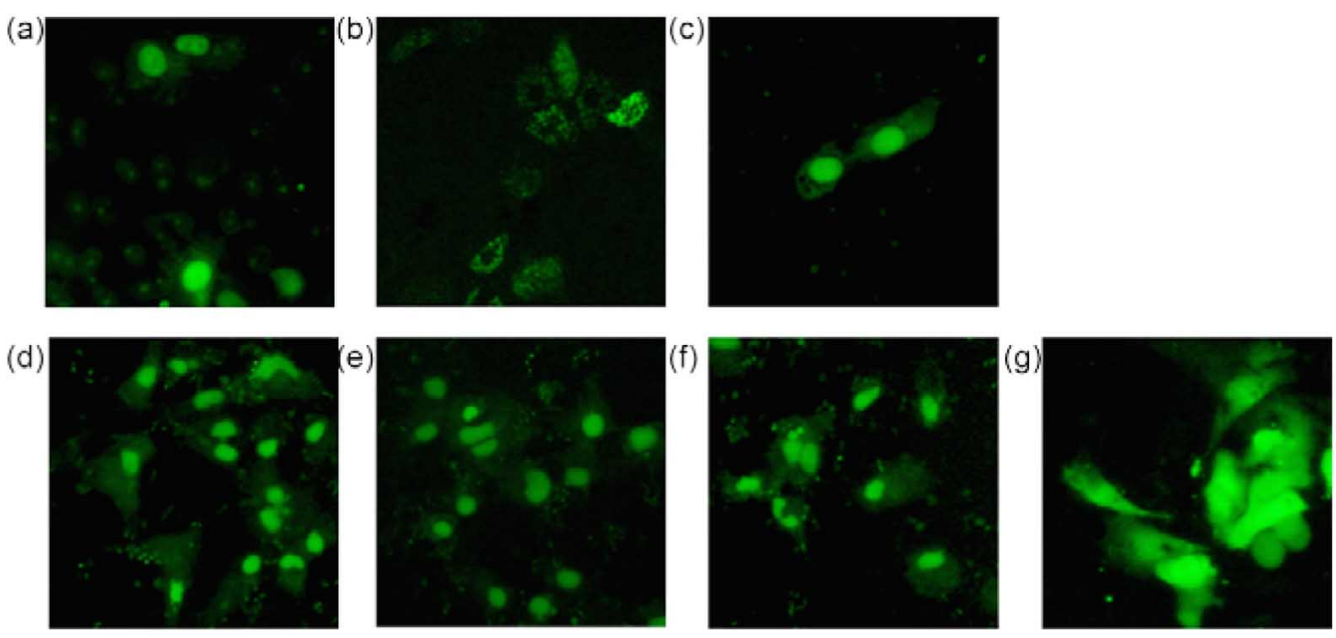

Fig. (4). Intracellular distribution of ORF3 and deletion mutants. (A) Schematic diagrams of ORF3 and deletion mutants. (B) PK-15 cells were transfected with recombinant plasmids containing defined coding region of ORF3, and incubated for $48 \mathrm{~h}$. The intracellular distributions of ORF3 (a), ORF3N52 (b), ORF3N53-104 (c) were examined with mouse specific immune serum by IFA. The GFP fusion proteins containing different N-terminal tags of ORF3 subunits, N53-68 (d), N53-85 (e), and N85-104 (f) were visualized with a fluorescence microscope. The location of each protein was scored as predominantly nuclear $(\mathrm{N}$ or $\mathrm{N}>\mathrm{C})$ or mostly cytoplasmic $(\mathrm{C}$ or $\mathrm{C}>\mathrm{N})$.

responsible for nuclear localization. The Chicken anemia virus VP3 protein (or apoptin) contains a C-terminal bipartite-type NLS and is believed to be prerequisite to its apoptotic activity in tumor cells $[27,28]$. Examination of the amino acid sequences of the C-terminal half region of ORF3 revealed two clusters of basic residues with homology to other NLS. The GFP fusion proteins containing either N5368 or N85-104 region of ORF3 could mediate the nuclear localization of GFP, thus confirming their role as a NLS.

In summary, ORF3 protein of PCV2 is capable of triggering apoptotic response in porcine PBMC. The apoptotic activity is correlated with the nuclear localization of ORF3. The biological function of ORF3 protein structure and the molecular mechanism involved in the induction of apoptosis in porcine PBMC are currently under study.

\section{CONFLICT OF INTEREST}

None declared.

\section{ACKNOWLEDGEMENTS}

This work was supported by a grant 98AS-9.2.4-BQ-B1 from the Bureau of Animal and Plant Health Inspection and
Quarantine, Council of Agriculture, Taiwan, Republic of China.

\section{REFERENCES}

[1] Ramamoorthy S, Meng XJ. Porcine circoviruses: a minuscule yet mammoth paradox. Anim Health Res Rev 2009; 10: 1-20.

[2] Allan GM, McNeilly F, Cassidy JP, et al. Pathogenesis of porcine circovirus; experimental infections of colostrum deprived piglets and examination of pig foetal material. Vet Microbiol 1995; 44: 4964 .

[3] Tischer I, Mields W, Wolff D, Vagt M, Griem W. Studies on epidemiology and pathogenicity of porcine circovirus. Arch Virol 1986; 91: 271-6.

[4] Allan GM, McNeilly F, Cassidy J, et al. Isolation of porcine circovirus-like viruses from pigs with a wasting disease in the USA and Europe. J Vet Diagn Invest 1998; 10: 3-10.

[5] Opriessnig T, Meng XJ, Halbur PG. Porcine circovirus type 2 associated disease: Update on current terminology, clinical manifestations, pathogenesis, diagnosis, and intervention strategies. J Vet Diagn Invest 2007; 19: 591-615.

[6] Chae C. A review of porcine circovirus 2-associated syndromes and diseases. Vet J 2005; 169: 326-36.

[7] Ellis J, Clark E, Haines D, et al. Porcine circovirus-2 and concurrent infections in the field. Vet Microbiol 2004; 98: 159-63.

[8] Krakowka S, Ellis J, McNeilly F, Waldner C, Allan G. Features of porcine circovirus-2 disease: correlations between lesions, amount 
and distribution of virus, and clinical outcome. J Vet Diagn Invest $2005 ; 17: 213-22$

[9] Mandrioli L, Sarli G, Panarese S, Baldoni S, Marcato PS. Apoptosis and proliferative activity in lymph node reaction in postweaning multisystemic wasting syndrome (PMWS). Vet Immunol Immunopathol 2004; 97: 25-37.

[10] Ostanello F, Caprioli A, Di Francesco A, et al. Experimental infection of 3-week-old conventional colostrum-fed pigs with porcine circovirus type 2 and porcine parvovirus. Vet Microbiol 2005; 108: 179-86.

[11] Sẽgales J, Allan GM, Domingo M. Porcine circovirus diseases. Anim Health Res Rev 2005; 6: 119-42.

[12] Liu J, Chen I, Du Q, Kwang J. Characterization of a previously unidentified viral protein in porcine circovirus type 2-infected cells and its role in virus-induced apoptosis. J Virol 2005; 79: 8262-74.

[13] Cheung AK. Transcriptional analysis of porcine circovirus type 2. Virology 2003; 305: 168-80.

[14] Mankertz A, Mankertz J, Wolf K, Buhk HJ. Identification of a protein essential for replication of porcine circovirus. J Gen Virol 1998; 79: 381-4.

[15] Nawagitgul P, Morozov I, Bolin SR, Harms PA, Sorden SD. Open reading frame 2 of porcine circovirus type 2 encodes a major capsid protein. J Gen Virol 2000; 81: 2281-7.

[16] Liu J, Zhu Y, Chen I, et al. The ORF3 protein of porcine circovirus type 2 interacts with porcine ubiquitin E3 ligase Pirh2 and facilitates p53 expression in viral infection. J Virol 2007; 81: 95607.

[17] Chang HW, Jeng CR, Lin TL, et al. Immunopathological effects of porcine circovirus type 2 (PCV2) on swine alveolar macrophages by in vitro inoculation. Vet Immunol Immunopathol 2006; 110: 207-19.

[18] Lin WL, Chien MS, Du YW, Wu PC, Huang C. The N-terminus of porcine circovirus type 2 replication protein is required for nuclear localization and ori binding activities. Biochem Biophys Res Commun 2009; 379: 1066-71.

[19] Wu PC, Chien MS, Tseng YY, et al. Expression of the porcine circovirus type 2 capsid protein subunits and application to an indirect ELISA. J Biotechnol 2008; 133: 58-64.

[20] Buck M, Burgess A, Stirzaker R, Krauer k, Sculley T. Epstein-Barr nuclear antigen 3A contains six nuclear-localization signals. J Gen Virol 2006; 87: 2879-84.

[21] Nielsen J, Vincent IE, Botner A, et al. Association of lymphopenia with porcine circovirus type 2 induced postweaning multisystemic wasting syndrome (PMWS). Vet Immunol Immunopathol 2003 92: 97-111.

[22] Resendes AR, Majó N, Sẽgales J, Mateu E, Calsamiglia M, Domingo M. Apoptosis in lymphoid organs of pigs naturally infected by porcine circovirus type 2. J Gen Virol 2004; 85: 283744.

[23] Kiupel M, Stevenson GW, Galbreath EJ, North A, HogenEsch H, Mittal SK. Porcine circovirus type 2 (PCV2) causes apoptosis in experimentally inoculated BALB/c mice. BMC Vet Res 2005; $1: 7$.

[24] Negoescu A, Lorimier P, Labat-Moleur F, et al. "In situ apoptotic cell labeling by the TUNEL method: improvement and evaluation on cell preparations". J Histochem Cytochem 1996; 44 (9): 959-68.

[25] Tsao CH, Su HL, Lin YL, et al. Japanese encephalitis virus infection activates caspase- 8 and -9 in a FADD-independent and mitochondrion-dependent manner. J Gen Virol 2008; 89: 1930-41.

[26] Liu J, Chen I, Du Q, Chua H, Kwang J. The ORF3 protein of porcine circovirus type 2 is involved in viral pathogenesis in vivo. $\mathrm{J}$ Virol 2006; 80: 5065-73

[27] Backendorf C, Visser AE, de Boer AG, et al. Apoptin: therapeutic potential of an early sensor of carcinogenic transformation. Annu Rev Pharmacol Toxicol 2008; 48: 143-69.

[28] Danen-Van Oorschot AA, Zhang YH, Leliveld SR, et al. Importance of nuclear localization of apoptin for tumor-specific induction of apoptosis. J Biol Chem 2003; 278: 27729-36.

Received: September 27, 2011

Revised: October 20,2011

Accepted: October 24, 2011

(C) Lin et al.; Licensee Bentham Open.

This is an open access article licensed under the terms of the Creative Commons Attribution Non-Commercial License (http: //creativecommons.org/licenses/by-nc/ 3.0/) which permits unrestricted, non-commercial use, distribution and reproduction in any medium, provided the work is properly cited. 